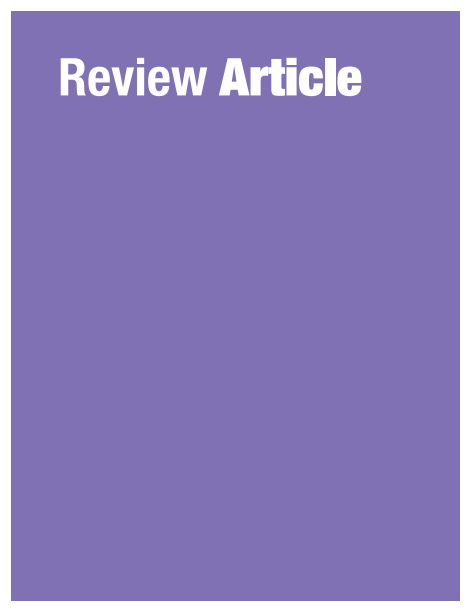

Submitted: 3 Mar 2016 Accepted: 2 Aug 2016 Online: 7 Dec 2016

\section{Updates on Knowledge, Attitude and Preventive Practices on Tuberculosis among Healthcare Workers}

\author{
Farhanah Abd Wahab1, Sarimah Abdullah', Jafri Malin \\ Abdullah $^{2}$, HASNAN Jaafar ${ }^{3}$, Sitı SuRaIYA Md Noor ${ }^{4}$, WAN \\ Mohd ZaHIRUddin Wan Mohammad ${ }^{5}$, Abdul AzIz Mohamed \\ Yusoff $^{6}$, JoHn Tharakan ${ }^{6}$, Shalini Bhaskar ${ }^{7}$, MuthuRAJU \\ Sangu $^{6}$, Mohd ShaH Mahmood ${ }^{8}$, FaUziah Kassim ${ }^{9}$, Md. HaniP \\ Rafia $^{10}$, Mohammed Safari Mohammed Haspani ${ }^{11}$, Azmı \\ Alias $^{11}$, Rogelıo Hernández Pando ${ }^{12}$
}

1 Unit of Biostatistics and Research Methodology, School of Medical Sciences, Health Campus, Universiti Sains Malaysia, 16150 Kubang Kerian, Kelantan, Malaysia

2 Center for Neuroscience Services and Research (P3Neuro), Health Campus, Universiti Sains Malaysia, 16150 Kubang Kerian, Kelantan, Malaysia

3 Department of Pathology, School of Medical Sciences, Health Campus, Universiti Sains Malaysia, 16150 Kubang Kerian, Kelantan, Malaysia

4 Department of Medical Microbiology and Parasitology, School of Medical Sciences, Health Campus, Universiti Sains Malaysia, 16150 Kubang Kerian, Kelantan, Malaysia

5 Department of Community Medicine, School of Medical Sciences, Health Campus, Universiti Sains Malaysia, 16150 Kubang Kerian, Kelantan, Malaysia

6 Department of Neurosciences, School of Medical Sciences, Health Campus, Universiti Sains Malaysia, 16150 Kubang Kerian, Kelantan, Malaysia

7 Gleneagles Medical Center, 1, Jalan Pangkor, Georgetown, 10050 Georgetown, Penang, Malaysia

8 Forensic Medicine, Hospital Kuala Lumpur, 50586 Jalan Pahang, Wilayah Persekutuan Kuala Lumpur, Malaysia

9 Department of Pathology, Hospital Kuala Lumpur, 50586 Jalan Pahang, Wilayah Persekutuan Kuala Lumpur, Malaysia

${ }^{10}$ Department of Neurology, Hospital Kuala Lumpur, 50586 Jalan Pahang, Wilayah Persekutuan Kuala Lumpur, Malaysia

${ }^{11}$ Department of Neurosurgery, Hospital Kuala Lumpur, 50586 Jalan Pahang, Wilayah Persekutuan Kuala Lumpur, Malaysia

12 Department of Pathology, National Institute of Medical Sciences and Nutrition "Salvador Zubiran", Avenida Vasco de Quiroga No. 15, Sección 16, Mexico, D.F. 14000

To cite this article: Farhanah AW, Sarimah A, Jafri Malin A, Hasnan J, Siti Suraiya MN, Wan Mohd Zahiruddin WM, et al. Updates on knowledge, attitude and preventive practices on Tuberculosis among healthcare workers. Malays $J$ Med Sci. 2016;23(6):25-34. http://dx.doi.org/10.21315/mjms2016.23.6.3

To link to this article: http://dx.doi.org/10.21315/mjms2016.23.6.3 


\begin{abstract}
Ranking as the most communicable disease killer worldwide, tuberculosis, has accounted with a total of 9.6 million new tuberculosis cases with 1.5 million tuberculosis-related deaths reported globally in 2014. Tuberculosis has remain as an occupational hazard for healthcare workers since 1920 s and due to several tuberculosis outbreaks in healthcare settings in the early 1990s, the concern about the transmission to both patients and healthcare workers has been raised. Healthcare workers have two to three folds greater the risk of active tuberculosis than the general population. Several studies on knowledge, attitude and practices on tuberculosis among healthcare workers worldwide have revealed that majority of the participated healthcare workers had good knowledge on tuberculosis. Most of the healthcare workers from South India and South Africa also reported to have positive attitude whereas a study in Thailand reported that most of the healthcare providers have negative attitude towards tuberculosis patients. Nevertheless, majority of the healthcare workers have low level of practice on tuberculosis prevention. An improved communication between healthcare workers and the patients as well as their families is the key to better therapeutic outcomes with good knowledge, attitude and preventive practice towards tuberculosis.
\end{abstract}

Keywords: tuberculosis, healthcare, health knowledge, attitudes, practice

\section{Introduction}

Tuberculosis (TB) is globally ranked as the most infectious disease (1). The World Health Organization (WHO) reported that there were 9 million cases of TB in 2013 and 1.5 million TBrelated deaths (2). In 2014, according to recent fact sheets by WHO, there were a total of 9.6 million new TB cases with 1.5 million deaths from the disease worldwide (1). The estimated TB incidence rates for year 2014, according to WHO, appear in Figure 1 (3). The Millennium Development Goal (MDG), which was to reverse the spread of TB by 2015, has successfully been met: an average $1.5 \%$ of TB incidence has fallen per year since 2000 , and, recently, incidence is $18 \%$ lower than it was in 2000 (1).

The recent Stop TB Strategy as the global plan for the next 5-year investment, 2016-2020, is the End TB strategy. It focuses on ending TB and moving forward from the limited measures that have thus far only involved controlling the disease (4). In 2001, the Global Plan to Stop TB was founded. The Global Plan was a roadmap for a five-year period aimed at combating TB (5). WHO depicted the global trends in estimated rates of TB incidence for 1990-2014, as well as prevalence and mortality rates for 1990-2015 (Figure 2) (5). Tuberculosis, by definition, is caused by a bacterium called Mycobacterium tuberculosis (MTB), which commonly affects and presents in the lungs, resulting in pulmonary $\mathrm{TB}$, but also manifests in other parts of the body such as the kidneys, spine and brain (through the lymphatics and blood vessels). When these other areas are affected, the disease is known as extrapulmonary TB (6).
This article focuses on the epidemiology of TB, knowledge, attitudes and practices for prevention of $\mathrm{TB}$ among healthcare workers, as well as preliminary local data among family members of $\mathrm{TB}$ patients regarding $\mathrm{TB}$ prevention.

\section{Epidemiology of TB among Healthcare Workers}

An occupational hazard for healthcare workers, especially nurses and physicians, cases of $\mathrm{TB}$ have been reported since the twenties (7). The threat of TB, however, receives little attention as an occupational hazard (8). In the early nineties, concern about TB transmission to both patients and healthcare workers was elevated due to several TB outbreaks in healthcare settings (8). World Health Organization reported that healthcare workers who care for infectious TB patients are at risk of infection based on recent studies of the risk of nosocomial transmission in developing countries (9).

Healthcare workers' risk of active TB disease is estimated to be two- to three-fold greater than the general population (10). Certain work locations such as inpatient $\mathrm{TB}$ facilities, laboratories and internal medicine and emergency facilities, as well as individuals who fit into various occupational categories such as radiology technicians, patient attendants, nurses, ward attendants, paramedics and clinical officers are all associated with a higher risk of active TB disease (11). Moreover, Costa et al. (12) added that healthcare workers are in the higher 
Review Article | KAP on TB among healthcare workers

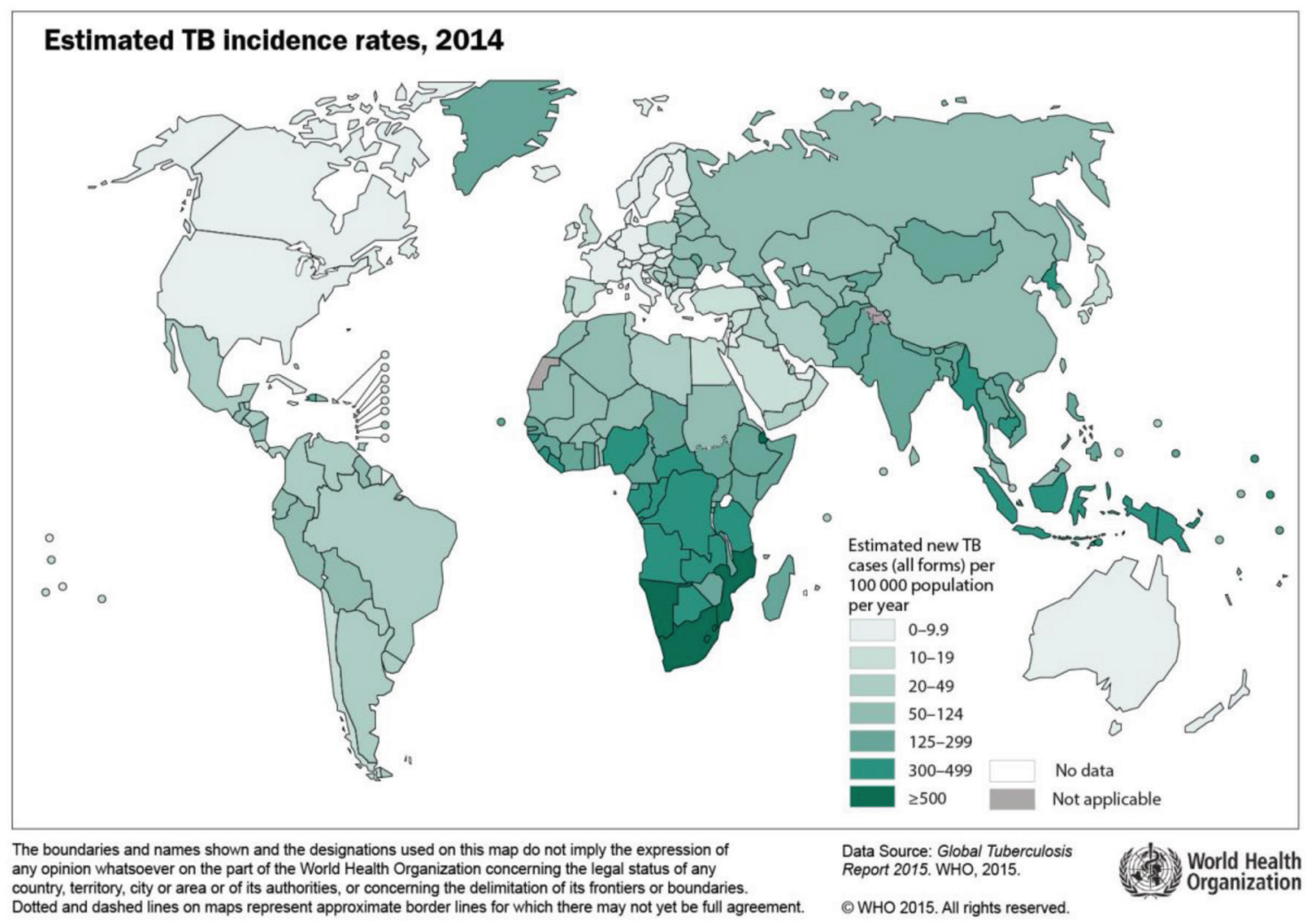

Figure 1. Global estimated TB incidence rates for year 2014

(Source: Global TB Report 2015 (3))

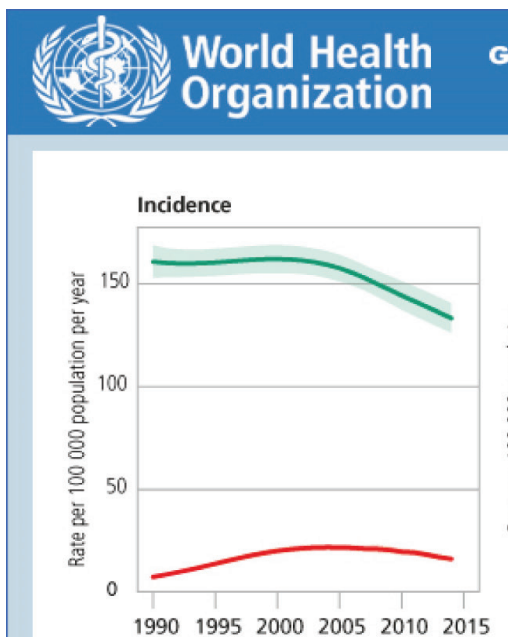

\section{Global trends in estimated rates of TB incidence (1990-2014) and prevalence and mortality rates (1990-2015)}

Left Estimated incidence rate including HIV-positive TB (green) and estimated incidence rate of HIV-positive TB (red). Centre and right: The horizontal dashed lines represent the Stop TB Partnership targets of a $50 \%$ reduction in prevalence and mortality rates by 2015 compared with 1990 . Shaded areas represent uncertainty bands. Mortality excludes TB deaths among HIV-positive people.

Figure 2. Global trends in estimated rates of TB incidence (1990-2014) and prevalence and mortality rates (1990-2015)

(Source: Global TB Report 2015 (3)) 
risk group of TB infection due to inadequate ventilation of working spaces and procedures involving contaminated aerosols, which favour transmission from an active disease, in the hospital setting.

Healthcare workers' exposure to TB will increase as the number of patients seeking TB treatment at health facilities increases, concomitant with the re-emergence of TB cases due to a high influx of immigrants from high TBburden countries, increasing number of HIV/ AIDs cases, transmission within overcrowded settings and emergence of multi-drug resistant TB (13). Improper implementation of infection control measures has resulted in the occurrence of nosocomial TB transmission. A healthcare worker who is sitting in proximity to an individual infected with TB has about four times greater the risk of TB infection (14). The risk of TB infection, however, varies widely based on different occupational groups and working conditions (15).

The occurrence of TB cases among healthcare workers for those who came from countries with low, intermediate and high TB incidence accounted for about 67 cases/100,000 persons, 91/100,000 persons and 1,180/100,000 persons, respectively, with an average of 34 (IQR 18-108) with 12,689 (IQR 2,979-57,279) persons-year being infected (16). From another perspective, nosocomial exposure was attributed to the risk of $\mathrm{TB}$ disease among healthcare workers with a range of 25 to 5,361 per 100,000 yearly, as reported in a systematic review of healthcare workers in low- and middle-income countries (11). Indeed, exposure to the risks in healthcare settings correlated with the incidence of TB cases among healthcare workers (16).

As for the prevalence of latent tuberculosis infection (LTBI) among healthcare workers ( $\mathrm{HCWs}$ ), on average, the annual risk of incidence among healthcare workers is $54 \%$ (range $33 \%-$ $79 \%$ ) with a range of 69 to 5,780 per 100,000 (11). As in another study, the occurrence of LTBI among healthcare workers accounted for an average of 23 with 731 persons infected annually (16). However, the reported cases of active TB disease were less well-documented among HCWs, although the estimation of LTBI globally is more than $50 \%$ among them (10). Additionally, a recent study in Santiago among healthcare workers disclosed that the LTBI prevalence is $15.4 \%$, and, among the healthcare workers, physicians have the highest prevalence (21.8\%), followed by nurses (19.6\%) (17).
According to a definition provided by the Ministry of Health Malaysia (MOH), healthcare workers are a group of people who work in healthcare facilities. The group includes nurses, physicians, nursing and medical students, dental workers, laboratory workers and others (18). Sabah, one of the two states in East Malaysia, has about two times higher the incidence of TB among healthcare workers than the general population, where the average incidence is 280.4 per 100,000 population over the past five years (14). Moreover, Sabah, in 2012, among all states in Malaysia, contributed the highest number of TB cases among healthcare workers, with 4,426 cases (19.5\%) out of 22,710 cases, followed by other states-Selangor, Sarawak and Johor, respectively $(14,19,20)$.

As of 2014, a report by the local media on 25 healthcare workers working in 11 general hospitals in Malaysia who were infected with TB raised concerns about the safety of healthcare settings in Malaysia (21). MOH depicted the estimated incidence of TB among Ministry of Health workers from year 2007 until 2010 (Table 1) (18). Nevertheless, a continuous increase in the number of TB cases among healthcare workers was accounted for with 192 cases in 2011 and 221 cases in 2012 (18). A study performed at the University of Malaya Medical Centre in Kuala Lumpur concluded that the level of TB exposure correlated with the occupational risk of healthcare workers-though they were already protected with BCG vaccination-where approximately half (50.1\%) of them were found to have a tuberculin skin test (TST) reaction of 10 $\mathrm{mm}$ or more, while $26.2 \%$ had TST reaction of 15 $\mathrm{mm}$ or more (21).

Table 1. Estimated incidence of tuberculosis among Ministry Health workers of year 2007-2010

(Source: Annual report Ministry of Health 2012 (19))

\begin{tabular}{lcccc} 
& \multicolumn{4}{c}{ Year } \\
\cline { 2 - 5 } & $\mathbf{2 0 0 7}$ & $\mathbf{2 0 0 8}$ & $\mathbf{2 0 0 9}$ & $\mathbf{2 0 1 0}$ \\
$\begin{array}{l}\text { Incidence } \\
\begin{array}{l}\text { (Per 100,000 } \\
\text { workers) }\end{array}\end{array}$ & 65.71 & 80.59 & 71.42 & 97.86 \\
No. of Cases & 92 & 119 & 124 & 182 \\
\hline
\end{tabular}

As an intermediate TB-burden country, the incidence of LTBI among healthcare workers in Malaysia per year was comparatively low, with 9.9/100 workers (22). Additionally, the 
prevalence of LTBI among healthcare workers at selected hospitals in Klang Valley, Selangor, as reported through a study by Rafiza et al. (13), was comprehensively $10.6 \%$. The LTBI prevalence among healthcare workers was interrelated with factors of duration of employment (11 years or more), ages 35 and above, a history of contacts with active TB patients, history working as a nurse and being male (13). Furthermore, employment periods and improper use of respiratory protection during high-risk procedures were the main risk factors for $\mathrm{TB}$ among healthcare workers after controlling other factors such as age, gender and history of contact with active TB patients outside the workplace (14). In worldwide studies, generally, the notification rate of $\mathrm{TB}$ incidence among healthcare workers was reported higher than in the general population $(10,11,14,16)$.

The dynamic system of life itself consists of three pillars: knowledge, attitude and practice (23). Survey on knowledge, attitude and practice acts as a representative study of a particular population through collecting information on what is known (knowledge), believed (attitude) and done in action (practice) connected to a specific topic (24). Therefore, conducting studies on the knowledge, attitude and practice of a population are crucial for any successful TB control programmes to identify the incident, transmission, treatment and control of TB disease through community involvement (25).

\section{Knowledge of TB among Healthcare Workers}

By definition, information that is acquired or gained is considered to be knowledge (23). From another perspective, knowledge is defined as what people know about certain subjects (24). Hashim et al. (25), in a study of knowledge, attitudes and practices, surveyed healthcare workers and TB patients in Iraq. Their responses revealed that 492 (98.4\%) out of 500 healthcare workers had a 'good' score for knowledge of TB. TB transmission mode through respiratory tract was correctly answered by $98.2 \%$ of the healthcare workers, while $90 \%$ said it is treatable, and only $12.6 \%$ of them were oblivious that it is caused by a bacterium (25). The respondents also accurately answered that risk factors of TB are continuous close contact with an active TB patient (83.6\%) followed by overcrowding (80.8\%), humidity (68.4\%) and under-nutrition $(67.8 \%)$, whilst $87 \%$ of them answered that the six months' duration of antiTB treatment course is necessary, especially to patients of PTB (25).

In another study of $\mathrm{TB}$ among healthcare workers in Vellore District, Tamil Nadu, South India (26), $86 \%$ of them were knowledgeable about $\mathrm{TB}$ disease. In terms of transmission and symptoms of $\mathrm{TB}, 95 \%$ of them correctly said that $\mathrm{TB}$ is transmitted via airborne route through coughing and sneezing, while 92\% said shaking hands with a TB patient will not spread the TB germs. Also, good nutritional intake is believed by $75 \%$ of the healthcare workers to be helpful in preventing TB disease; $21 \%$ of them conservatively believe in the power of prayer (34). In Thailand, 56\% of healthcare providers were found to possess a 'good' level of knowledge of TB, while $43.87 \%$ had a 'fair' level of knowledge. $71.23 \%$ of the providers with good knowledge were well-informed about the nature of the disease (27).

Furthermore, assessment among health staff at basic health care facilities in rural Vietnam revealed that $90 \%$ of them were aware of the nature of TB disease: they knew it is caused by a bacterium; persistent cough was chosen as the most frequent symptom (98\%) and $97 \%$ said it is curable (28). In TB treatment procedures, only 81 (32\%) out of 253 of the staff could perform 'directly observed treatment' (DOT) properly in $\mathrm{TB}$ patients. In terms of practice efficiency in managing TB patients, $90 \%$ of them responded with the accurate way to diagnose the suspected TB cases. The study also disclosed that an increased level of knowledge among the health staff is correlated with participation in TB training and higher medical education (28).

A study in the Berea District of Lesotho, South Africa on occupational exposure to TB reported that the majority of healthcare workers (86.1\%) have a 'fair' score for knowledge (29). The majority of them (90.7\%) knew that TB is an airborne infectious disease and it is curable (97.7\%). TB as a symptom of chronic cough (94.7\%) was answered by most of the healthcare workers, followed by night sweats (84.5\%), weight loss (79.1\%), and fever (53.5\%). In TB investigation, $96.9 \%$ of them agreed that the best diagnostic test is by sputum smear, and $99.2 \%$ said that treatment should be completed within the duration of six-months. The healthcare workers were also concerned about the BCG vaccination: $58.6 \%$ said that it is not preventive towards TB disease (29). 
A preliminary study of knowledge, attitudes and practices towards TB prevention was done in 2013 from two selected hospitals. Five family members were interviewed based on a questionnaire of knowledge, attitudes and practices (KAP) of TB cases among nurses (30). It was found that only $20 \%$ of them had good knowledge. TB infection is commonly associated with lungs was correctly answered by $80 \%$ of the family members, while $80 \%$ said it is treatable and curable. However, $60 \%$ of them were still unaware that TB is caused by a bacterium called Mycobacterium tuberculosis. All of them believed that smoking (100\%) is the main risk factor for TB, apart from alcohol and drug use (40\%), other chronic diseases (20\%), overcrowding and malnutrition (20\%) and poverty (20\%). As for treatment of $\mathrm{TB}$, the completion of a six-month course of anti-TB drug was correctly chosen by $80 \%$ of the family members.

All of the family members thought that TB can spread from an infected individual commonly through coughing (100\%), sneezing (80\%), talking (60\%) and spitting (60\%). They also agreed that a handshake (80\%) with the infected TB individual will not spread the germs. Common symptoms that related to $\mathrm{TB}$, according to the family members, were fatigue (80\%), loss of appetite (80\%), coughing producing blood or sputum (60\%), weight loss (60\%), chest pain (60\%), shortness of breath (60\%) and fever (40\%). The majority of them (80\%) agreed that sputum examination and chest $\mathrm{x}$-rays are the common diagnostic tests for TB. As for TB prevention, $80 \%$ of them said that people should avoid going near patients who have an active TB lesion, and $60 \%$ believed in simply following a balanced diet.

\section{Attitude of TB among Healthcare Workers}

Attitude, by meaning, reflects on how people feel about certain subjects or issues (24). It also describes a way of thinking about a situation (23). In other views, attitude refers to the tendency to react in a distinctive way to certain situations, to see and interpret events pertaining to certain tendencies or to assemble opinions into an interrelated structure (31). Wu (26), in a study on knowledge and attitudes of healthcare workers towards TB in Vellore District, Tamil Nadu, South India revealed that $80 \%$ of the healthcare workers felt sympathy towards TB patients and desired to help, whilst $8 \%$ of them were concerned but chose to stay away.

Lertkanokkun et al. (27), in a study of healthcare providers in Thailand, outlined that almost $60 \%$ of the providers had negative attitudes towards TB patients. However, 56.13\% of them had positive attitudes, especially in terms of providing TB services (66.98\%) and the use of TB-control systems (60\%). Previous studies showed that negative attitudes of providers towards the actual treatment success resulted in a high treatment dropout rate (27). Research has proven that better therapeutic outcomes result from improved communication between $\mathrm{TB}$ patients and their families and healthcare workers (32).

In a study done in the Berea District of Lesotho, South Africa, almost all healthcare workers (93\%) were found to have positive attitudes towards TB infection control (29). The majority of them (97.7\%) agreed to complete TB treatment in case of being diagnosed and to improve their eating habits to avoid malnutrition as an approach to TB prevention. Furthermore, $96.1 \%$ of them willingly agreed to teach patients and their co-workers about TB prevention, 95.4\% are always ready to be screened for TB if needed and $94.6 \%$ willingly agreed to attend training related to TB prevention (29). Globally, special attention was given to the clinical aspect in most of the TB-control efforts, rather than the human aspect, although people's perceptions of $\mathrm{TB}$ and patients' non-adherence to anti-TB treatment were the most important factors in the emergence of acquired resistance (33).

Meanwhile from local preliminary data, it was found that $40 \%$ of five family members of TB patients have positive attitudes towards TB prevention. All of the family members felt empathy towards TB patients (100\%) and willing to help and interact with the patients (100\%) although $60 \%$ of them still felt doubt and fear about the potential of transmission of TB infection when interacting with TB patients. They also agreed that, as a family member, it is necessary to have good communication with $\mathrm{TB}$ patients (100\%). Nevertheless, only $80 \%$ of them used appropriate terminologies when talking to the TB patients. 


\section{TB Practice among Healthcare Workers}

World Health Organization defines practice as how people behave (24). It means the reflection and application of rules and knowledge that lead to actions $(23,31)$. Yu et al. (34), in a study to assess knowledge of attitudes towards and practices associated with pulmonary TB among physicians in St. Luke's Medical Center, Philippines, found that, as TB infection prevention, 39\% of doctors opened their windows, whilst $24.4 \%$ tried to keep a safe distance, and $\mathbf{1 2 . 2 \%}$ wore masks. Although there was a concern about TB infection, 19.5\% out of 38 physicians did not take any necessary preventative approaches while examining TB patients (34). They expressed that, for TB treatment and its compliance, improved communication with the patients is essential, in addition to always keeping up to date with information on TB by reading periodicals, attending academic meetings and searching the Internet (34).

Bhebhe et al. (29), in their evaluation of occupational exposure to TB among healthcare workers in the Berea District of Lesotho, South Africa, revealed that half of them (52.7\%) received a 'fair' score for practice, while only $10.9 \%$ received a 'good' practice score on TB prevention. In terms of administrative control measures, the majority of health care workers (93.8\%) said that the screening of TB patients for HIV was done on a regular basis, while only $26.4 \%$ educated patients on TB infection control. Environment control measures mostly consisted of isolation of patients and ward separation (78.3\%) and improving air ventilation and sunlight by opening windows (69\%) (29). The healthcare workers also practiced hand hygiene (76\%) and the use of a respirator mask (71.3\%) for personal protection measures, but only half of them (54.4\%) made use of the appropriate respirator, N-95.

In another related study, 90\% of the health staff at basic health care facilities in Bavi District in rural Vietnam accurately responded on the correct ways to diagnose suspected TB cases (28). Regarding patients' management measure during TB treatment course, the practice was reported low (22.1\%). However, the majority of the staff (89.7\%) responded appropriately to questions about dealing with TB patients with symptoms of coughing and weight loss. Although during treatment course the reported practice was lower, among staff members who had attended a TB training course, it was higher (28). Additionally, Nicol et al. (35) revealed that TB training for healthcare workers could reduce the likelihood of $\mathrm{TB}$ infection and that there was a correlation between training attendance and low TST positivity test incidence. Training is considered to be one of the related factors that influences healthcare workers regardless of cultural and ethnic background, practice settings, preferred sources of information and learning styles (36).

Local preliminary data for five family members of TB patients revealed that $40 \%$ of them received good scores for practice in TB preventive measures. $40 \%$ of the family members have read about TB disease before, and only $20 \%$ regularly stay up to date with new insights about TB prevention measures. In terms of personal TB prevention control, $60 \%$ of them regularly practice hand-washing, and 40\% have always worn respiratory protection and provided it to the TB patient with a cough, as well as guided the patient as to the proper way of disposing of sputum. Lastly, $40 \%$ of the family members have also guided the patient regarding cough etiquette and worn gloves when needed.

\section{Conclusion}

In accordance with several studies on TB knowledge, attitudes and practices worldwide, it can be concluded that healthcare workers have better knowledge, attitude and practice as compared with family members of $\mathrm{TB}$ patients. The nature of the healthcare setting itself could be the reason behind the higher rate of knowledge about TB disease among healthcare workers. This denotes that the healthcare worker's role, especially with regards to their knowledge, attitudes and practices in the healthcare setting, is vital to ensuring public welfare.

\section{Acknowledgement}

We acknowledge the Research University Team grant from Universiti Sains Malaysia number 1001/PPSP/853001. 


\section{Conflict of Interest}

None

\section{Funds}

Grant from Universiti Sains Malaysia number 1001/ PPSP/853001.

\section{Authors' Contribution}

Conception and design: FAW, JMA, RHP

Analysis and interpretation of the data: FAW, SA, WMZWM

Drafting of the article: FAW, SA, JMA, WMZWM

Critical revision of the article for important intellectual content: AAMY, JT, SB

Final approval of the article: FAW, SA, JMA, WMZWM

Provision of study materials or patients: HJ, SSMN

Statistical espertise: SA, WMZWM

Obtaining of funding: JMA

Administrative, technical or logistic support: JMA

Collection and assembly of data: FAW, RHP, HJ, SSMN, AAMY, JT, SB

\section{Correspondence}

Assoc. Prof. Dr. Sarimah Abdullah

MD (USM), MComMed (Epidemiology and

Biostatistics) (USM)

Unit of Biostatistics and Research Methodology

School of Medical Sciences

Health Campus

Universiti Sains Malaysia

16150 Kubang Kerian, Malaysia

Tel: +609-767 6829

Fax: +609-765 3370

Email: sarimah@usm.my

\section{References}

1. World Health Organization. Media centre: Tuberculosis. 2016a. Retrieved February $17^{\text {th }}$, 2016, from http://www.who.int/mediacentre/ factsheets/fs104/en/\#

2. World Health Organization. Media centre: Tuberculosis. 2014. Retrieved November 4th, 2014, from http://www.who.int/mediacentre/ factsheets/fs104/en/\#

3. World Health Organization. Global Tuberculosis report 2015. Switzerland: WHO Press. 2015a

4. World Health Organization. The global plan to end TB. 2016b. Retrieved February 17th, 2016, from http://www.stoptb.org/global/plan/plan2/
5. World Health Organization. The global plan to stop TB. 2015a. Retrieved January 5th, 2015, from http://stoptb.org/global/plan/default.asp

6. World Health Organization. Global health observatory: Tuberculosis (TB). 2012. Retrieved March 4th, 2012, from http://www.who.int/gho/ tb/en/index.html

7. Sepkowitz KA, Friedman, CR, Hafner A, Kwok D, Manoach MF, Martinez D, et al. Tuberculosis among urban health care workers: A study using restriction fragment length polymorphism typing. Clinical Infection Disease. 1995;21(5):10981102. http://dx.doi.org/10.1093/clinids/21.5.1098

8. Ramazan K, Onder E, Ziya D, Sebnem E, Nurcan B, Basak D. Risk of Tuberculosis infection among healthcare workers in a tertiary-care hospital in Ankara, Turkey. Infection Control. 2004;25:1067-1071. http://dx.doi.org/10.1017/ So195941700077481

9. World Health Organization. Guideline for the prevention of tuberculosis in health care facilities in resource-limited settings. Switzerland: WHO Press; 1999.

10. Tudor C, Van Der Walt M, Margot B, Dorman SE, Pan WK, Yenokyan G, Farley, J.E. Tuberculosis among health care workers in KwaZulu-Natal, South Africa: a retrospective cohort analysis. BMC Public Health. 2014;14:891. http://dx.doi. org/10.1186/1471-2458-14-891

11. Joshi R, Reingold AL, Menzies D, Pai M. Tuberculosis among health-care workers in low- and middle-income countries: A systematic review. PLoS Medicine. 2006;3(12):e494. http:// dx.doi.org/10.1371/journal.pmed.o030494

12. Costa JCT, Silva R, Ferreira J, Nienhaus A. Active tuberculosis among health care workers in Portugal. J Bras Pneumol. 2011;37(5):636-645.

13. Rafiza S, Rampal KG, Tahir A. Prevalence and risk factors of latent tuberculosis infection among health care workers in Malaysia. BMC Infectious Disease. 2011;11(9):1-7.

14. Jelip J, Mathew GG, Yusin T, Dony, JF, Singh $\mathrm{N}$, Ashaari M, et al. Risk factors of tuberculosis among health care workers in Sabah, Malaysia. Tuberculosis. 2004;84:19-23. http://dx.doi. org/10.1016/j.tube.2003.08.015 
15. Nassaji M, Ghorbani R. Risk factors for latent tuberculosis infection among healthcare workers in a university-affiliated hospital. South Afr $J$ Epidemiol Infect. 2012;27(1):30-33.

16. Baussano I, Nunn P, Williams B, Pivetta E, Bugiani M, Scano F. Tuberculosis among health care workers. Emerg Infect Dis. 2011;17(3):488494. http://dx.doi.org/10.3201/eid1703.100947

17. Borotto S, Gamez D, Diaz D, Martinez Y, Ferrer AI, Velasquez Y, et al. Latent tuberculosis infection among health care workers at a general hospital in Santiago de Cuba. Int J Tuberc Lung Dis. 2011;15(11):1510-1514.

18. Ministry of Health Malaysia. Guidelines on prevention and management of tuberculosis for health care workers in Ministry of Health Malaysia. Malaysia: MOH Malaysia; 2012a.

19. Ministry of Health Malaysia. Annual Report Ministry of Health 2012. Malaysia: $\mathrm{MOH}$ Malaysia; 2012b.

20. Ministry of Health Malaysia. Health indicators 2013: Indicators for monitoring and evaluation of strategy health for all. Malaysia: $\mathrm{MOH}$ Malaysia; 2013.

21. Tan LH, Kamarulzaman A. Preventing tuberculosis in healthcare workers of the radiology department: a Malaysian perspective. Biomedical Imaging and Intervention Journal. 2006;2(1):e3. http://dx.doi.org/10.2349/biij. 2.1.e3

22. Swarna Nantha Y. A review of tuberculosis research in Malaysia. Med $J$ Malaysia. 2014;69:88-102.

23. Jain M, Sawla L, Mathur A, Nihlani T, Ayair U, Prabu D, Kulkarni S. Knowledge, attitude and practice towards droplet and airborne isolation precautions amongs dental health care professionals in India. Med Oral Patol Oral Cir Bucal. 2010;1:15(6):e957-e961. http://dx.doi. org/10.4317/medoral.15.e957

24. World Health Organization. Advocacy, communication and social mobilization for TB control: A guide to developing knowledge, attitude and practice surveys. Switzerland: WHO Press; 2008.
25. Hashim DS, Al Kubaisy W, Al Dulayme A. Knowledge, attitudes and practices survey among health care workers and tuberculosis patients in Iraq. Eastern Mediterranean Health Journal. 2003;9(4):718-731.

26. Wu I. Knowledge and attitudes of healthcare workers towards tuberculosis patients and the experiences of tuberculosis patients regarding healthcare workers in Vellore District, Tamil Nadu, South India. 2010. Retrieved March 13, 2012, from http://www.ilep.org.uk/fileadmin/ uploads/Documents/Infolep_Documents/Stigma_ Research_Workshop/13_Wu_tb_india.pdf

27. Lertkanokkun S, Okanurak K, Kaewkungwal J, Meksawasdichai N. Healthcare providers' knowledge, attitudes \& practices regarding tuberculosis care. JITMM2O12 Proceedings. 2013;2:1-10.

28. Hoa NP, Diwan VK, Thorson AE. Diagnosis and treatment of pulmonary tuberculosis at basic health care facilities in rural Vietnam: A survey of knowledge and reported practices among health staff. Health Policy. 2005;72:1-8.

29. Bhebhe LT, Van Rooyen C, Steinberg WJ. Attitudes, knowledge and practices of healthcare workers regarding occupational exposure of pulmonary tuberculosis. Afr J Prm Healthcare Fam Med. 2014;6(1):597-602. http://dx.doi. org/10.4102/phcfm.v6i1.597

30. Badran IG. Knowledge, attitude and practice the three pillars of excellence and wisdom: a place in the medical profession. Eastern Mediterranean Health Journal. 1995;1(1):8-16.

31. Martin LR, Williams SL, Haskard KB, DiMatteo MR. The challenge of patient adherence. Ther Clin Risk Manag. 2005;1(3):189-199.

32. Bacay-Domingo MCN, Ong-Lim AL. A descriptive study of the knowledge, attitudes and practices on tuberculosis among treatment partners of pediatric patients in Tarlac city. PIDSP Journal. 2009;10(1).

33. Yu CT, Zantua RRR, Sto. Tomas LJH. Pulmonary tuberculosis: Knowledge, attitudes and practices of selected physicians in a tertiary-care hospital. Phil J Microbiol Infect Dis. 2002;31(1):1-8. 
34. Nicol L, Mehtar S, Dheda K, Adams S, Walt MVD, Osman M. A systematic review of the epidemiology of and programmatic response to $T B$ in health care workers in South Africa. South Africa: Stellenbosch University Press; 2014.
35. Miller JA. The perceptions and beliefs of healthcare workers about clients with tuberculosis. 2007. (Master dissertation, University of Auckland, 2007). Retrieved from https://cdn.auckland.ac.nz/assets/arts/ Departments/anthropology/documents-publications/ miller.pdf 